\title{
Sugammadex is associated with shorter hospital length of stay after open lobectomy for lung cancer: a retrospective observational study
}

Seung Won Song, Kyung Yeon Yoo, Yong Sung Ro, Taehee Pyeon, Hong-Beom Bae* and Joungmin Kim * (D)

\begin{abstract}
Background: Sugammadex is associated with few postoperative complications. Postoperative pulmonary complications (PPC) are related to prolonged hospitalizations. Present study explored whether the use of sugammadex could reduce PPCs and thereby reduce hospital length of stay (LOS) after lung surgery.

Methods: We reviewed the medical records of patients who underwent elective open lobectomy for lung cancer from January 2010 to December 2015. Patients were divided into the sugammadex group and pyridostigmine group.

The primary outcome was hospital LOS and secondary outcomes were postoperative complications and overall survival at 1 year. The cohort was subdivided into patients with and without prolonged LOS to explore the effects of sugammadex on outcomes in each group. Risk factors for LOS were determined via multivariate analyses. After propensity score matching, 127 patients were assigned to each group.

Results: Median hospital LOS was shorter (10.0 vs. 12.0 days) and the incidence of postoperative atelectasis was lower (18.1 vs. 29.9\%) in the sugammadex group. However, no significant difference in overall survival between the groups was seen over 1 year (hazard ratio, 0.967; 95\% confidence interval, 0.363 to 2.577). Sugammadex was a predictor related to LOS (exponential coefficient $0.88 ; 95 \% \mathrm{Cl} 0.82-$ 0.95).

Conclusions: Our data suggest that sugammadex is a preferable agent for neuromuscular blockade (NMB) reversal than cholinesterase inhibitors in this patient population.

Trial registration: This study registered in the Clinical Research Information Service of the Korea National Institute of Health (approval number: KCT0004735, Date of registration: 21 January 2020, Retrospectively registered).
\end{abstract}

Keywords: Sugamadex, Pyridostigmine, Length of stay, Lobectomy

\footnotetext{
* Correspondence: nextphil2@jnu.ac.kr; tca77@hanmail.net

Department of Anesthesiology and Pain Medicine, Chonnam National University Medical School, Chonnam National University Hospital, 160,

Baekseo-ro, Dong-gu, Gwangju 501-746, South Korea
}

(c) The Author(s). 2021 Open Access This article is licensed under a Creative Commons Attribution 4.0 International License, which permits use, sharing, adaptation, distribution and reproduction in any medium or format, as long as you give appropriate credit to the original author(s) and the source, provide a link to the Creative Commons licence, and indicate if changes were made. The images or other third party material in this article are included in the article's Creative Commons licence, unless indicated otherwise in a credit line to the material. If material is not included in the article's Creative Commons licence and your intended use is not permitted by statutory regulation or exceeds the permitted use, you will need to obtain permission directly from the copyright holder. To view a copy of this licence, visit http://creativecommons.org/licenses/by/4.0/. The Creative Commons Public Domain Dedication waiver (http://creativecommons.org/publicdomain/zero/1.0/) applies to the data made available in this article, unless otherwise stated in a credit line to the data. 


\section{Background}

Lung resection surgery is associated with a high incidence of postoperative pulmonary complications (PPCs), including prolonged air leak, atelectasis, pneumonia, empyema, and acute respiratory distress syndrome [1]. PPCs are associated with prolonged hospitalizations, admissions to the intensive care unit (ICU), and hospital re-admissions, as well as increased morbidity, mortality, and healthcare expenditure [2-6]. Residual neuromuscular blockade (NMB) after emergence from anesthesia can lead to pulmonary complications including hypoxia, pulmonary collapse, and acute respiratory failure $[7,8]$. In addition, complete pharmacological reversal improves pulmonary outcomes by reducing the likelihood of residual neuromuscular blockade after anesthesia [9].

Anticholinesterases such as neostigmine or pyridostigmine are commonly used to reverse NMB during general anesthesia. Despite the use of relatively short-acting agents (e.g., rocuronium), which decrease the incidence of residual $\mathrm{NMB}$, the incidence of residual $\mathrm{NMB}$ is reported to $82 \%$ at $6 \mathrm{~min}$ post administration of neostigmine [10]. And it has various cholinergic side effects including bradycardia, hypotension, bronchoconstriction, and airway secretion $[11,12]$. Sugammadex is modified gamma-cyclodextrin compound that selectively binds to steroidal non-depolarizing neuromuscular blocker by forming a 1:1 complex. In contrast to anticholinesterase, it shows rapid and reliable neuromuscular block reversal [13]. It reduces postoperative complications and improves patient outcomes [14].

Hospital length of stay (LOS) is considered an important quality metric for recovery from surgery and anesthesia [15]. The length of time patients spend in hospital is a good representation of the amount of hospital resources utilized, such as bed utilization, staffing, and equipment [16]. To date, few studies have evaluated the relationship between neuromuscular block reversal with sugammadex and patient outcomes including LOS with controversial results in different surgeries [12, 17-19].

We hypothesized that there would be a difference in the LOS due to PPC when the NMB reversed with sugammadex compared pyridostigmine after open lobectomy for lung cancer. We investigated the relationship between reversal agent and LOS/postoperative complication rate/overall survival, and identified risk factors associated with prolonged LOS in these patients.

\section{Methods}

\section{Study population and data collection}

This study was approved by the institutional review board of Chonnam National University Hwasun Hospital (approval number: CNUHH-2019-207, 19 Dec. 2019) and registered in the Clinical Research Information Service of the Korea National Institute of Health (approval number: KCT0004735). Data was collected retrospectively by Seung Won Song from electronic patient medical records at Chonnam National University Hwasun Hospital. Patients 19 years of age or older and of American Society of Anesthesiologists (ASA) physical status I to III who underwent elective open lobectomy for lung cancer from January 2010 to December 2015 were included. Sugamadex was introduced in our hospital in 2013, and has been used for thoracic surgery since 2014. The information collection period was set to make the frequency of use of the two drugs similar. There are various surgical procedures for lung cancer, but only open lobectomy was included in the study in order to reduce the variance between the types of surgery. Excluded from analyses were patients who were paralyzed with neuromuscular blocker other than rocuronium (e.g., cisatracurium), reversed with an agent other than pyridostigmine or sugammadex (e.g., neostigmine due to its different pharmacokinetic features such as onset, duration, potency), transferred to ICU for recovery from anesthesia, or missing any medical records.

Patients were divided into sugammadex and pyridostigmine groups according to the type of reversal agent used during surgery. The following data were collected for the study. Preoperative data: age, sex, height, weight, body mass index (BMI), forced expiratory volume in $1 \mathrm{~s}$ (FEV1) / forced vital capacity (FVC), and preoperative comorbidities (including ASA physical status, diabetes mellitus [DM], hypertension [HTN], chronic kidney disease [CKD], heart failure [HF], coronary arterial disease [CAD], chronic obstructive pulmonary disease [COPD], and asthma). Intra-operative data: location of surgery (right or left), surgery time, agent used for neuromuscular block reversal. Postoperative data: LOS after surgery, duration of stay in postanesthesia care unit (PACU), postoperative complications (pyrexia, dyspnea, air leak > 5 days, atelectasis, pneumonia, mechanical ventilator use, hemodynamic instability, and ICU admission), and type of patient-controlled analgesia (epidural or intravenous). In-hospital standard medication regimen was used for pain control. In case of epidural catheter placement, fentanyl with chirocaine patient controlled analgesia (PCA) was used. Patients without epidural catheter were received intravenous fentanyl PCA. No additional block was performed.

Postoperative complications were examined by reviewing medical records. Pyrexia was defined as having a tympanic membrane temperature greater than $38.0^{\circ} \mathrm{C}$. Dyspnea was defined as presenting with complaints of feeling short of breath or showing blue-tinged fingers or lips and/or use of accessory muscles or chest muscles to breathe. Hemodynamic instability was defined as a fall in the systolic blood pressure below $90 \mathrm{mmHg}$ with symptoms related to hypotension, including chest discomfort 
and altered consciousness level, requiring immediate pharmacological rescue (e.g., vasopressor or inotrope). Atelectasis and pneumonia were diagnosed based on a serial postoperative plain chest radiograph routinely checked until discharge.

The primary endpoint was the difference in LOS after open lung lobectomy between reversal with sugammadex and pyridostigmine. The secondary endpoints were differences in postoperative complications and overall survival between the two reversal agents. We performed additional analyses after dividing the cohorts into two subgroups (patients with prolonged LOS (LOS $>14$ days) vs. those without $(\operatorname{LOS} \leq 14$ days)). Prolonged LOS was defined as hospitalization beyond 14days, as suggested in a previous report [20]. Intra- and postoperative outcomes were compared between the two groups in each subgroup. Multivariate poisson and logistic regression using stepwise variable selection was used to identify perioperative risk factors associated with LOS.

\section{Statistical analysis}

Continuous variables are presented as the mean \pm standard deviation (SD) for normally distributed data or median (interquartile range, IQR) for non-normally distributed data and were compared using an unpaired Student $t$-test or Wilcoxon rank-sum test, as appropriate. Normality was verified based on the Shapiro-Wilk test or by inspecting histograms or Q-Q plots. Categorical variables are presented as numbers (percentage, \%) and were compared using Pearson's $\chi^{2}$ test or Fisher's exact test. The Kaplan-Meier method was applied for analyses of discharge rate and survival rate [21, 22]. We investigated the outpatient visit to investigate the patient's one-year survival. If there were any hospital visit history after 1 year from surgery, patient was assumed to survive after 1 year. But if there were any record declaring death of patient, we concluded that the patient was dead. The variables were compared using the log-rank test and the Cox proportional hazard ratio was estimated for survival analyses. $P$ value $<0.05$ was considered statistically significant; all tests were two-sided.

LOS is a naturally skewed distribution in most cohorts [16], so we constructed a multivariate Poisson regression model for LOS as a response variable to identify risk factors that increase the LOS. A multivariate logistic regression model was also constructed to identify risk factors associated with prolonged LOS. Covariates were classified into demographic predictors and intra- or postoperative predictors to construct two different models. Initially, a univariate regression was performed to screen covariates associated with the response variable. Covariates with a $p$ value $<0.2$ in univariate regression were included in the multivariate regression model. Final covariates were selected using the forward and backward stepwise elimination method based on Akaike Information Criterion. Exponential coefficients and their 95\% confidence interval (CI) for the Poisson model and odds ratio (OR) and their 95\% CI for the logistic model was estimated for each covariate in the final model.

Propensity score matching was performed to reduce potential selection bias. Covariates used in propensity score matching were as follows. Age, sex, ASA physical status, DM, HTN, CKD, HF, CAD, COPD, asthma, operation site, FEV1/FVC, operation time, BMI. Nearest neighbor method was used and ratio was 1:1. $\mathrm{R}$ code used in analysis was as follows. This approach estimated the probability of individuals receiving sugammadex as an agent for neuromuscular block reversal and allows for comparison with pyridostigmine-receiving patients with similar demographic and clinical characteristics. The score of each patient was calculated by estimating the probability to be assigned to each neuromuscular block reversal agent using multivariate logistic regression. The balance of the two groups was assessed based on standardized differences. All statistical analyses and tests were performed using $\mathrm{R}$, a software environment for statistical computing ( $\mathrm{R}$ version 3.6.0; The $\mathrm{R}$ Foundation for Statistical Computing, Vienna, Austria). Propensity score matching was performed using package MatchIt in R program (version 3.0.2).

\section{Results}

During the study period, 266 patients underwent open lobectomy for lung cancer at our institution. Of those patients, 9 were excluded due to cisatracurium use, ICU transfer after surgery, or missing medical records. A total of 257 patients were enrolled; 127 patients received pyridostigmine (pyridostigmine group) and 130 patients received sugammadex (sugammadex group) for NMB reversal. After propensity score matching, 127 patients in each group were included in the final analyses (Fig. 1). Demographic and clinical characteristics at baseline are summarized in Table 1 and were comparable between the two groups.

The collected data included 4 thoracic surgeons and 5 anesthesiologists (excluding residents). The initial dose of rocuronium was $0.8-1.0 \mathrm{mg} / \mathrm{kg}$. Pyridostigmine was $0.1-0.2 \mathrm{mg} / \mathrm{kg}$ and sugammadex was $1.5-2 \mathrm{mg} / \mathrm{kg}$ for reversal of NMB. The use of sugammadex continued after it was decided at the anesthesiology faculty meeting, which led to more intensive NMB during surgery. The degree of NMB during anesthesia was monitored using the MechanoSensor ${ }^{\mathrm{T} x}$ DatexOhmeda GE Healthcare NMT-EMG (Helsinki, Finland). However, it was excluded from the analysis due to inconsistent medical records. A double lumen endotracheal tube was used for one-lung ventilation during surgery, and the surgical approach for the affected area was a conventional posterior 


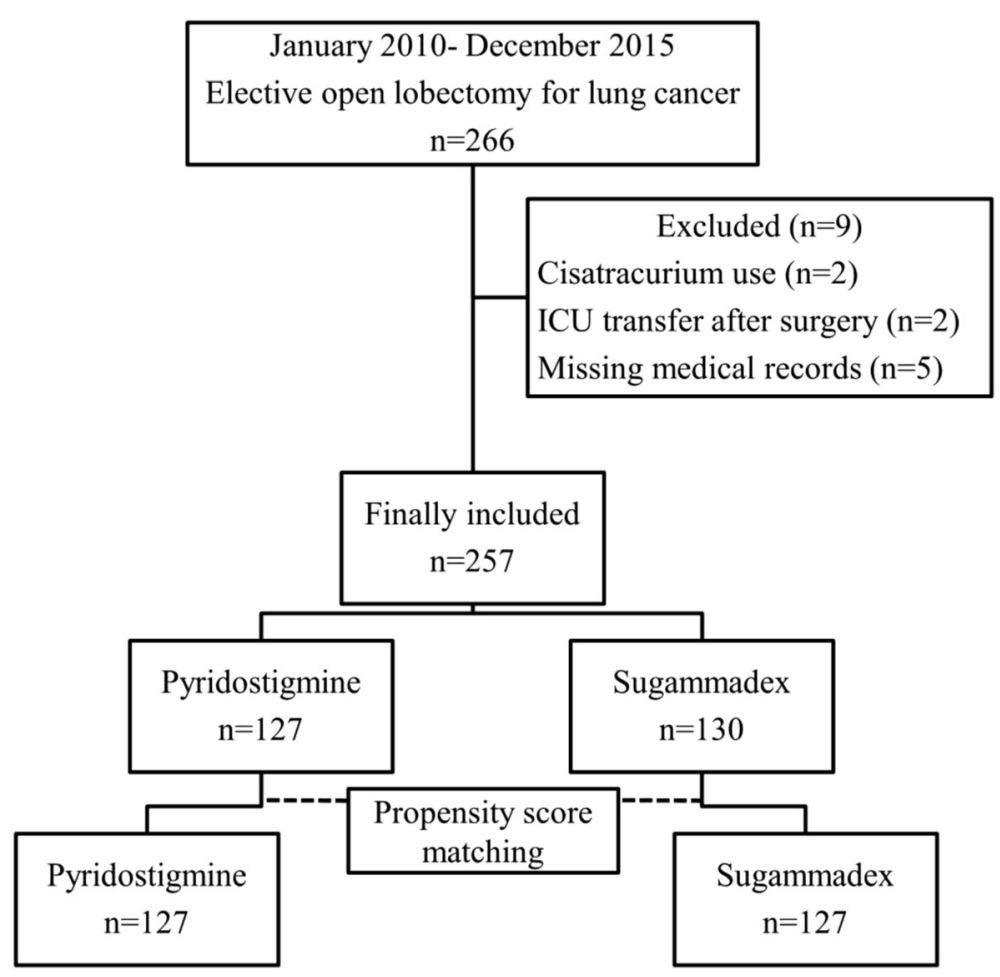

Fig. 1 Flow chart of patient selection

Table 1 Demographic and clinical characteristics at baseline of matched cohort

\begin{tabular}{|c|c|c|c|}
\hline Variable & Pyridostigmine $(n=127)$ & Sugammadex $(n=127)$ & $p$ value \\
\hline Age (year) & $66.0(59.5-71.0)$ & $67.0(60.0-72.0)$ & 0.358 \\
\hline Male sex & $92(72.4)$ & $96(75.6)$ & 0.668 \\
\hline Height (cm) & $163.0(159.0-168.5)$ & $163.0(158.0-168.0)$ & 0.640 \\
\hline Weight (kg) & $62.0(56.0-67.0)$ & $61.0(56.0-69.5)$ & 0.817 \\
\hline BMI $\left(\mathrm{kg} \mathrm{m}^{-2}\right)$ & $23.1(21.5-25.5)$ & $23.5(21.3-25.7)$ & 0.445 \\
\hline ASA PS & & & 0.238 \\
\hline 1 & $14(11.0)$ & $19(15.0)$ & \\
\hline$\|$ & $104(81.9)$ & $93(73.2)$ & \\
\hline III & $9(7.1)$ & $15(11.8)$ & \\
\hline Diabetes mellitus & $22(17.3)$ & $27(21.3)$ & 0.525 \\
\hline Hypertension & $55(43.3)$ & $55(43.3)$ & 1.000 \\
\hline CKD & $5(3.9)$ & $2(1.6)$ & 0.443 \\
\hline Heart failure & $3(2.4)$ & $0(0.0)$ & 0.245 \\
\hline$C A D$ & $14(11.0)$ & $12(9.4)$ & 0.836 \\
\hline COPD & $28(22.0)$ & $31(24.4)$ & 0.766 \\
\hline Asthma & $3(2.4)$ & $0(0.0)$ & 0.245 \\
\hline Operation site (right) & $85(66.9)$ & $76(59.8)$ & 0.297 \\
\hline
\end{tabular}

Data are presented as $\mathrm{n}(\%)$, median (interquartile range)

$B M I$ Body mass index, ASA PS American Society of Anesthesiologists physical status, CKD Chronic kidney disease, CAD Coronary arterial disease, COPD Chronic obstructive pulmonary disease 
Table 2 Intra- and postoperative outcomes of matched cohort

\begin{tabular}{|c|c|c|c|}
\hline Variable & Pyridostigmine $(n=127)$ & Sugammadex $(n=127)$ & $p$ value \\
\hline Surgery time (min) & $210.0(180.0-255.0)$ & $210.0(180.0-252.0)$ & 0.067 \\
\hline PCA & & & 0.004 \\
\hline Epidural & $110(86.6)$ & $90(70.9)$ & \\
\hline Intravenous & $17(13.4)$ & $37(29.1)$ & \\
\hline LOS (days) & $12.0(9.5-16.5)$ & $10.0(8.0-15.0)$ & 0.005 \\
\hline PACU stay (min) & $65.0(60.0-80.0)$ & $60.0(55.0-75.0)$ & 0.290 \\
\hline \multicolumn{4}{|l|}{ Events in PACU } \\
\hline Dyspnea & $4(3.1)$ & $3(2.4)$ & 1.000 \\
\hline $\mathrm{HDI}$ & $7(5.5)$ & $4(3.1)$ & 0.538 \\
\hline \multicolumn{4}{|l|}{ Events in Ward } \\
\hline Pyrexia & $38(29.9)$ & $28(22.0)$ & 0.198 \\
\hline Dyspnea & $17(13.4)$ & $10(7.9)$ & 0.222 \\
\hline Air leak $>5$ days & $27(21.3)$ & $26(20.5)$ & 1.000 \\
\hline Atelectasis & $38(29.9)$ & $23(18.1)$ & 0.040 \\
\hline Pneumonia & $9(7.1)$ & $6(4.7)$ & 0.594 \\
\hline MV & $3(2.4)$ & $2(1.6)$ & 1.000 \\
\hline $\mathrm{HDI}$ & $7(5.5)$ & $1(0.8)$ & 0.072 \\
\hline ICU & $5(3.9)$ & $2(1.6)$ & 0.443 \\
\hline
\end{tabular}

Data are presented as $\mathrm{n}(\%)$, median (interquartile range)

PCA Patient controlled analgesia, LOS Length of stay, PACU Post anesthesia care unit, HDI Hemodynamic instability, MV Mechanical ventilator use, ICU Intensive care unit admission

Table 3 Intra- and postoperative outcomes of matched cohort with and without a prolonged length of stay

\begin{tabular}{|c|c|c|c|c|c|c|}
\hline & \multicolumn{3}{|l|}{ LOS $\leq 14$ Days } & \multicolumn{3}{|l|}{ LOS > 14 Days } \\
\hline & Pyridostigmine $(n=83)$ & Sugammadex $(n=93)$ & $\overline{p \text { value }}$ & Pyridostigmine $(n=44)$ & Sugammadex $(n=34)$ & $p$ value \\
\hline Surgery time (min) & $210.0(180.0-240.0)$ & $205.0(175.0-240.0)$ & 0.230 & $240.0(210.0-270.0)$ & $235.0(185.0-255.0)$ & 0.457 \\
\hline \multicolumn{7}{|l|}{ PCA } \\
\hline Epidural & $72(86.7)$ & $62(66.7)$ & 0.003 & $38(86.4)$ & $28(82.4)$ & 0.865 \\
\hline Intravenous & $11(13.3)$ & $31(33.3)$ & & $6(13.6)$ & $6(17.6)$ & \\
\hline LOS (days) & $10.0(9.0-12.0)$ & $9.0(7.0-10.0)$ & 0.002 & $19.0(16.0-26.0)$ & $19.0(16.0-23.0)$ & 0.537 \\
\hline PACU stay (min) & $60.0(55.0-75.0)$ & $60.0(55.0-75.0)$ & 0.611 & $70.0(60.0-90.0)$ & $60.0(55.0-75.0)$ & 0.007 \\
\hline \multicolumn{7}{|l|}{ Events in PACU } \\
\hline Dyspnea & $1(1.2)$ & $2(2.2)$ & 1.000 & $3(6.8)$ & $1(2.9)$ & 0.801 \\
\hline $\mathrm{HDI}$ & $4(4.8)$ & $3(3.2)$ & 0.878 & $3(6.8)$ & $1(2.9)$ & 0.801 \\
\hline \multicolumn{7}{|l|}{ Events in ward } \\
\hline Pyrexia & $21(25.3)$ & $16(17.2)$ & 0.258 & $17(38.6)$ & $12(35.3)$ & 0.947 \\
\hline Dyspnea & $5(6.0)$ & $4(4.3)$ & 0.861 & $12(27.3)$ & $6(17.6)$ & 0.466 \\
\hline Air leak $>5$ days & $3(3.6)$ & $6(6.5)$ & 0.610 & $24(54.5)$ & $19(55.9)$ & 1.000 \\
\hline Atelectasis & $21(25.3)$ & $11(11.8)$ & 0.034 & 17 (38.6) & $12(35.3)$ & 0.947 \\
\hline Pneumonia & $0(0.0)$ & $1(1.1)$ & 1.000 & $9(20.5)$ & $5(14.7)$ & 0.720 \\
\hline MV & $1(1.2)$ & $0(0.0)$ & 0.954 & $2(4.5)$ & $2(5.9)$ & 1.000 \\
\hline $\mathrm{HDI}$ & $3(3.6)$ & $0(0.0)$ & 0.206 & $4(9.1)$ & $1(2.9)$ & 0.526 \\
\hline $\mathrm{ICU}$ & $1(1.2)$ & $0(0.0)$ & 0.954 & $4(9.1)$ & $2(5.9)$ & 0.921 \\
\hline
\end{tabular}

Data are presented as $\mathrm{n}(\%)$ or median (interquartile range)

PCA Patient controlled analgesia, LOS Length of stay, PACU Post anesthesia care unit, MV Mechanical ventilator use, HDI Hemodynamic instability, ICU Intensive care unit admission 
lateral thoracotomy in the lateral position. In the following cases, an anesthesiologist discussed with a thoracic surgeon to determine whether to extubate: Difficulty breathing before surgery, hypoxemia (blood oxygen saturation $<90 \%$ ) frequently occurring during one-lung ventilation, or excessive fluid administration $(\geq 30 \mathrm{ml} /$ $\mathrm{kg})$.

Table 2 shows intra- and postoperative outcomes of matched cohorts in both pyridostigmine and sugammadex groups. Median hospital LOS was significantly shorter in the sugammadex group than in the pyridostigmine group (10.0 days (IQR $8.0-15.0$ days) vs. 12.0 days (IQR 9.5-16.5 days) $(p=0.005)$. The incidence of atelectasis (18.1 vs. $29.9 \%, p=0.040)$ was lower and Epidural PCA (70.9 vs. $86.6 \%, p=0.004$ ) was less used in the sugammadex group than in the pyridostigmine group. However, no differences were found regarding other postoperative complications reviewed between the two reversal agents.

Intra- and postoperative outcomes of matched cohorts in patients with and without prolonged LOS are shown in Table 3. Median LOS was 1 day shorter in the sugammadex group than in the pyridostigmine group ( 9.0 days [IQR 7.0-10.0 days] vs. 10.0 days [IQR 9.0-12.0 days], $p=0.002$ ) in patients without prolonged LOS, whereas it did not differ between the two groups in patients with prolonged LOS (19.0 days [IQR 16.0-23.0 days] vs. 19.0 days [IQR 16.0-26.0 days], $p=0.537)$. And, PACU stay time was significantly shorter when reversed with sugammadex than with pyridostigmine $(60.0$ vs. 70.0 $\min , p=0.007$ ) in patients with prolonged LOS. Among postoperative complications, the incidence of atelectasis was significantly lower in the sugammadex group than in the pyridostigmine group (11.8 vs. $25.3 \%, p=0.034)$ in patients without prolonged LOS, but did not differ between the groups (35.3 vs. $38.6 \%, p=0.947)$ in patients with a prolonged LOS.

LOS was also analyzed based on the discharge rate to determine the proportion of discharged patients on each postoperative day during hospitalization (Fig. 2). Discharge rate was significantly higher in the sugammadex group throughout the admission period $(p=0.025$, Fig. 2a). Sugammadex also facilitated patient discharge compared to pyridostigmine in patients without prolonged LOS ( $p=0.0083$, Fig. $2 \mathrm{~b})$, but not in patients with prolonged LOS ( $p=0.41$, Fig. 2c).

All variables that were significant in univariate analyses were included in multivariate analyses to identify covariates associated with LOS in the propensity matched total study cohort (Table 4). In multivariate analyses, demographic predictors included four variables (age $\geq 65$ years, male sex, DM, COPD). COPD and male sex showed higher risk for prolongation of LOS. Age $\geq$ 65 years was associated with a $9 \%$ increase in LOS. By
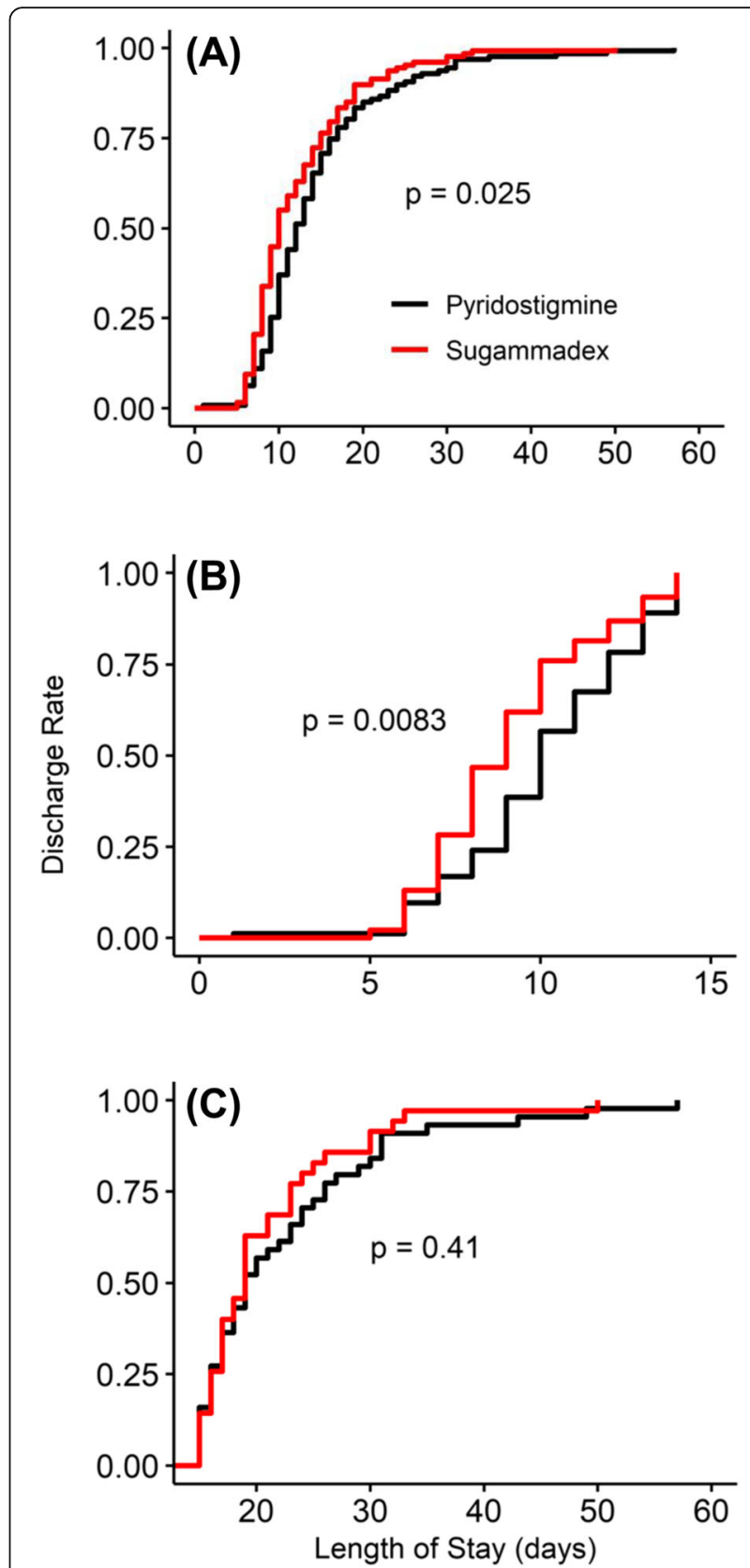

Fig. 2 Kaplan-Meier curve for discharge in all cohorts (a) and in patients without (b) and with (c) prolonged hospital stay

contrast, DM reduced the LOS by $18 \%$. The only intraoperative predictor was sugammadex, which reduced LOS by $12 \%$. Among the postoperative factors significant in univariate analyses, dyspnea, atelectasis, pneumonia, and air leak $>5$ days remained significant for increasing the risk for prolonged LOS. Pneumonia and air leak $>5$ days showed a higher risk for extended LOS. Dyspnea and atelectasis were also associated with increased hospitalization. 
Table 4 Predictors of length of stay after lobectomy for lung cancer in both sugammadex and pyridostigmine cohorts. Variables were selected from multivariable poisson regression model using forward selection and backward elimination based on the Akaike information criterion

\begin{tabular}{lll}
\hline & Exp Coef $(95 \% \mathrm{Cl})$ & $\boldsymbol{p}$ value \\
\hline Demographic predictors & $1.09(1.10-1.18)$ & 0.021 \\
Age $\geq 65 \mathrm{yr}$ & $1.27(1.16-1.38)$ & $<0.001$ \\
Male sex & $0.82(0.75-0.90)$ & $<0.001$ \\
Diabetes mellitus & $1.33(1.23-1.43)$ & $<0.001$ \\
COPD & & \\
Intra- or postoperative predictors & $0.88(0.82-0.95)$ & $<0.001$ \\
Sugammadex (vs. pyridostigmine) & $1.39(1.27-1.55)$ & $<0.001$ \\
Dyspnea & $1.21(1.12-1.30)$ & $<0.001$ \\
Atelectasis & $1.77(1.58-1.99)$ & $<0.001$ \\
Pneumonia & $1.40(1.33-1.46)$ & $<0.001$ \\
Air leak $>5$ days &
\end{tabular}

Exp Coef Exponential coefficient, Cl Confidence interval, COPD Chronic obstructive pulmonary disease

The Kaplan-Meier curves of overall survival in the propensity-matched cohort are illustrated in Fig. 3. The estimated 1-year survival rates were $93.4 \%$ (89.1 to $97.9 \%$ ) in the pyridostigmine group and $93.7 \%$ (89.6 to $98.0 \%$ in the sugammadex group. There were no significant differences between the two groups in overall survival with an unadjusted hazard ratio for death at 1 year of $0.967 ; 95 \% \mathrm{CI}, 0.0 .363$ to 2.577 ( $p=0.947$ ).

\section{Discussion}

In this retrospective study, we observed a median 2.0 day decrease in time from surgery to discharge, a significantly lower postoperative complication rate (e.g., atelectasis), and a similar mortality over 1 year after the surgery when reversed with sugammadex compared to pyridostigmine. Moreover, sugammadex was the only intraoperative predictor associated with reduced LOS.

Hospital LOS was decreased, as was the incidence of adverse postoperative outcomes (e.g., atelectasis) in patients reversed with sugammadex for $\mathrm{NMB}$, in line with previous studies that reported that the use of sugammadex is associated with $20 \%$ shorter LOS with reduced postoperative adverse outcomes after major abdominal surgery [12] and is associated with a 0.6 day shorter hospital LOS and a lower postoperative complication rate after laparoscopic gastric cancer surgery [18]. Residual NMB occurs in approximately $20-60 \%$ of surgical patients [23] and is associated with an increased incidence of PPCs (e.g., hypoxemia and atelectasis) [8]. On the other hand, sugammadex has been shown to reduce the incidence of residual $\mathrm{NMB}$ upon arrival in the PACU compared to other classic NMB reversal agents [24]. Therefore, sugammadex may decrease hospital LOS through its improved muscle relaxant reversal, leading to a reduction in PPCs and early patient discharge.

By contrast, Ledowski et al. [17] observed that overall hospital LOS after surgery did not differ between patients treated with sugammadex or acetylcholinesterase

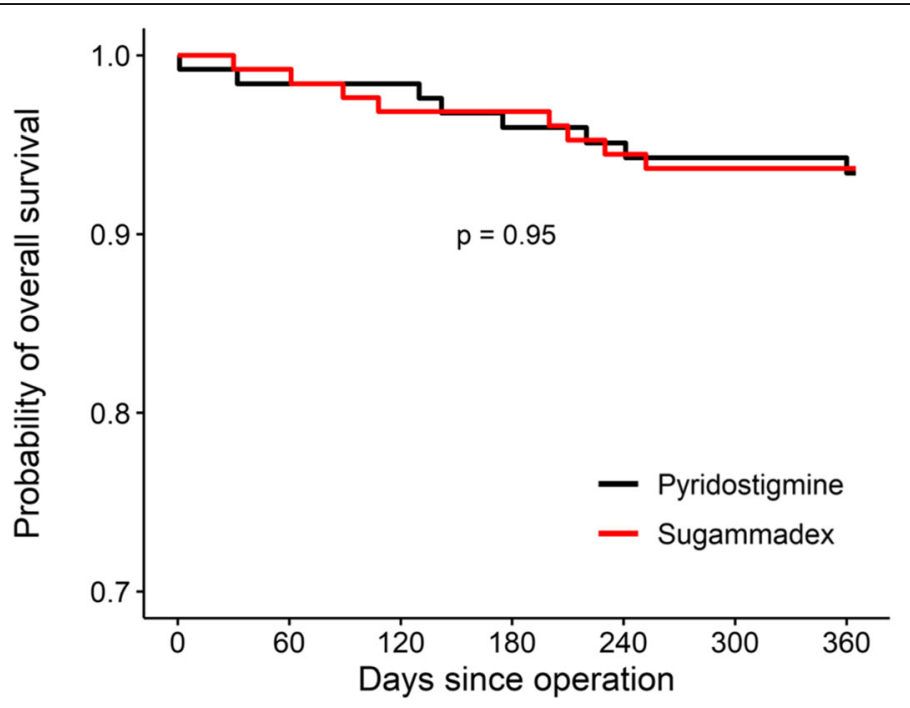

Number at risk

\begin{tabular}{|c|c|c|c|c|c|c|}
\hline \begin{tabular}{l|l} 
Pyridostigmine & 127 \\
Sugammadex & 127
\end{tabular} & $\begin{array}{l}124 \\
126 \\
\end{array}$ & $\begin{array}{l}123 \\
123 \\
\end{array}$ & $\begin{array}{l}117 \\
123\end{array}$ & $\begin{array}{l}114 \\
119 \\
\end{array}$ & $\begin{array}{l}111 \\
117\end{array}$ & $\begin{array}{l}110 \\
116\end{array}$ \\
\hline 0 & 60 & 120 & 180 & 240 & 300 & 360 \\
\hline
\end{tabular}

Fig. 3 Kaplan-Meier survival estimates of death from any cause 
inhibitors; the cause of this discrepancy remains unclear. It has been shown that postoperative residual NMB and associated adverse PPCs are more common in elderly patients than in younger patients [25]. Moreover, thoracic and abdominal procedures that reduce lung volume are associated with increased risk of developing atelectasis and postoperative complications [26]. Ledowski et al. [17] studied relatively young patients (mean age 50 years) who underwent surgical procedures including orthopedic, plastic, general, and others, whereas we studied elderly patients (mean age $\sim 66$ years) who underwent open lung surgery. Thus, different ages of surgical populations and type of surgery may be responsible for differences between the studies. Indeed, Ledowski et al. [17] demonstrated that NMB reversal with sugammadex significantly improves postoperative pulmonary outcomes compared to neostigmine, particularly in elderly patients.

It has previously been reported that poorly controlled acute postoperative pain is a risk factor associated with respiratory complications [27], and that postoperative pain may lead to the development of atelectasis because it can interfere with the normal activity of respiratory muscles and forced respiratory effort [28]. On the other hand, other studies have shown that epidural analgesia provides better postoperative pain control than systemic opioid administration in abdominal or open thoracotomy surgery $[29,30]$. In the present study, epidural patient-controlled analgesia was used less commonly in patients reversed with sugammadex than those reversed with pyridostigmine. The postoperative pain is expected to be more severe in the sugammadex group, but the hospital LOS was short and PPCs occurred less. These findings are in accordance with those of a recent study that showed that patients reversed with sugammadex had fewer postoperative complications and a shorter LOS despite more severe postoperative pain compared to those with neostigmine in patients who had undergone laparoscopic gastric cancer surgery [18].

Several studies have reviewed patients undergoing pulmonary resection for lung cancer and identified risk factors for prolonged hospital LOS [1, 20, 28, 31-34]. Some risk factors identified previously include older age [20,32,33], male sex [20], ASA physical status score [20,32], insulin-dependent diabetes [20], renal dysfunction [20], percentage predicted FEV1 [20,33], surgeon [33], smoking [20], COPD [32], and postoperative complications (e.g., pneumonia [32, 33], unplanned reintubation $[32,34]$, or prolonged ventilation [32, 34]). In this study, we confirmed the important risk factors for morbidity and LOS after lung resection (Table 4). In fact, the use of sugammadex is becoming increasingly common for NMB reversal, particularly in the elderly, with the advantage that it can reverse profound NMB, although reversal agent options are currently limited by price.
Overall survival 1 year after surgery did not differ between the two reversal agents (Fig. 3). Death after lung cancer surgery may be attributable to surgery-related major complications and to cancer progression. Although sugammadex decreases the incidence of PPCs and shortened hospital LOS in the present study, this agent is unlikely to significantly reduce surgery-related major complications. In addition, we found that once a patient reached a medically stable state and was discharged, the mortality after 1 year was not different across the type of reversal agent, suggesting that an advantage for sugammadex does not extend to the long term.

This study had several limitations. First, this is a small number, single center, retrospective study that is not free from bias in selection and treatment. Not all covariates were controlled, although the demographics and clinical characteristics were balanced by propensity score matching. Second, some fundamental intra- or postoperative covariates associated with respiratory complications were not collected. The degree of pain after surgery is considered an important factor associated with respiratory complications [27]. The severity of pain and opioid consumption were not assessed in this study. In addition, the total dose of neuromuscular blocking agent administered and depth of NMB at the time of reversal were not included in our analyses. Use of single or repeated doses [35] and depth of NMB at the time of reversal [36] are important factors that affect recovery after NMB. Third, diagnosis of atelectasis was entirely dependent on plain chest radiographs, although only relatively obvious cases of atelectasis seen on plain radiography were included. However, this technique for the diagnosis of postoperative lung collapse is less sensitive than computed tomography, which was not routinely performed after open lobectomy in our hospital. Finally, the extent of surgery are strongly related to patient outcomes. However, the cohorts analyzed were a highly selective group that underwent open lobectomy for lung cancer.

\section{Conclusion}

Compared with pyridostigmine, NMB reversal with sugammadex after open lung lobectomy for lung cancer was associated with a shorter hospital stay and a lower PPC, but with a similar mortality after 1 year. In particular, the effects of sugammadex on LOS was obvious in patients without prolonged LOS. Our data suggest that sugammadex is a preferable agent for NMB reversal than cholinesterase inhibitors in this patient population. However, further prospective, randomized, controlled, and sufficiently powered studies on larger patient populations are required. 


\section{Abbreviations}

PPC: Postoperative pulmonary complication; ICU: Intensive care unit; NMB: Neuromuscular blockade; LOS: Length of stay; ASA: American Society of Anesthesiologists; BMI: Body mass index; FEV1: Forced expiratory volume in $1 \mathrm{~s}$; FVC: Forced vital capacity; DM: Diabetes mellitus; HTN: Hypertension; CKD: Chronic kidney disease; HF: Heart failure; CAD: Coronary arterial disease; COPD: Chronic obstructive pulmonary disease; PACU: Postanesthesia care unit; PCA: Patient controlled analgesia; SD: Standard deviation; IQR: Interquartile range; Cl: Confidence interval; OR: Odds ratio

\section{Acknowledgements}

Not applicable.

\section{Authors' contributions}

Seung Won Song as a major contributor in writing the manuscript. Kyung Yeon Yoo and Yong Sung Ro contributed to the data analysis. Taehee Pyeon contributed to visualization. Hong-Beom Bae and Joungmin Kim contributed to conception and design. All authors read and approved the final manuscript.

\section{Funding}

The authors received no financial support for the research, authorship, and/ or publication of this article.

\section{Availability of data and materials}

Not applicable.

\section{Declarations}

\section{Ethics approval and consent to participate}

This study was approved by the institutional review board of Chonnam National University Hwasun Hospital (approval number: CNUHH-2019-207) and conformed to the declaration of Helsinki.

\section{Consent for publication}

No applicable.

\section{Competing interests}

The authors declare that they have no competing interests.

\section{Received: 3 November 2020 Accepted: 12 March 2021}

\section{Published online: 23 March 2021}

\section{References}

1. Ziarnik E, Grogan EL. Postlobectomy early complications. Thorac Surg Clin. 2015;25(3):355-64. https://doi.org/10.1016/j.thorsurg.2015.04.003.

2. Shander A, Fleisher LA, Barie PS, Bigatello LM, Sladen RN, Watson CB. Clinical and economic burden of postoperative pulmonary complications: patient safety summit on definition, risk-reducing interventions, and preventive strategies. Crit Care Med. 2011;39(9):2163-72. https://doi.org/10.1097/CCM. 0b013e31821f0522.

3. Needham DM, Davidson J, Cohen H, Hopkins RO, Weinert C, Wunsch H, Zawistowski C, Bemis-Dougherty A, Berney SC, Bienvenu OJ, Brady SL, Brodsky MB, Denehy L, Elliott D, Flatley C, Harabin AL, Jones C, Louis D, Meltzer W, Muldoon SR, Palmer JB, Perme C, Robinson M, Schmidt DM, Scruth E, Spill GR, Storey CP, Render M, Votto J, Harvey MA. Improving longterm outcomes after discharge from intensive care unit: report from a stakeholders' conference. Crit Care Med. 2012;40(2):502-9. https://doi.org/1 0.1097/CCM.0b013e318232da75.

4. Jencks SF, Williams MV, Coleman EA. Rehospitalizations among patients in the Medicare fee-for-service program. N Engl J Med. 2009;360(14):1418-28. https://doi.org/10.1056/NEJMsa0803563.

5. Dharmarajan K, Hsieh AF, Lin Z, Bueno H, Ross JS, Horwitz LI, Barreto-Filho JA, Kim N, Bernheim SM, Suter LG, Drye EE, Krumholz HM. Diagnoses and timing of 30-day readmissions after hospitalization for heart failure, acute myocardial infarction, or pneumonia. JAMA. 2013;309(4):355-63. https://doi. org/10.1001/jama.2012.216476.

6. Dimick JB, Chen SL, Taheri PA, Henderson WG, Khuri SF, Campbell DA Jr. Hospital costs associated with surgical complications: a report from the private-sector National Surgical Quality Improvement Program. J Am Coll Surg. 2004;199(4):531-7. https://doi.org/10.1016/j.jamcollsurg.2004.05.276.
7. Plaud B, Debaene B, Donati F, Marty J. Residual paralysis after emergence from anesthesia. Anesthesiology. 2010;112(4):1013-22. https://doi.org/10.1 097/ALN.0b013e3181cded07.

8. Murphy GS, Szokol JW, Marymont JH, Greenberg SB, Avram MJ, Vender JS. Residual neuromuscular blockade and critical respiratory events in the postanesthesia care unit. Anesth Analg. 2008;107(1):130-7. https://doi.org/1 0.1213/ane.0b013e31816d1268.

9. Hunter JM. Reversal of residual neuromuscular block: complications associated with perioperative management of muscle relaxation. $\mathrm{Br} J$ Anaesth. 2017;119(suppl_1):i53-62.

10. Raval AD, Uyei J, Karabis A, Bash LD, Brull SJ. Incidence of residual neuromuscular blockade and use of neuromuscular blocking agents with or without antagonists: a systematic review and meta-analysis of randomized controlled trials. J Clin Anesth. 2020;64:109818. https://doi.org/10.1016/j. jclinane.2020.109818.

11. Fuchs-Buder T, Meistelman C, Raft J. Sugammadex: clinical development and practical use. Korean J Anesthesiol. 2013;65(6):495-500. https://doi.org/1 0.4097/kjae.2013.65.6.495.

12. Oh TK, Oh AY, Ryu JH, Koo BW, Song IA, Nam SW, Jee HJ. Retrospective analysis of 30-day unplanned readmission after major abdominal surgery with reversal by sugammadex or neostigmine. Br J Anaesth. 2019;122(3): 370-8. https://doi.org/10.1016/j.bja.2018.11.028.

13. Nicholson WT, Sprung J, Jankowski CJ. Sugammadex: a novel agent for the reversal of neuromuscular blockade. Pharmacotherapy. 2007;27(8):1181-8. https://doi.org/10.1592/phco.27.8.1181.

14. Kheterpal S, Vaughn MT, Dubovoy TZ, Shah NJ, Bash LD, Colquhoun DA, Shanks AM, Mathis MR, Soto RG, Bardia A, Bartels K, McCormick PJ, Schonberger RB, Saager L. Sugammadex versus neostigmine for reversal of neuromuscular blockade and postoperative pulmonary complications (STRONGER): a multicenter matched cohort analysis. Anesthesiology. 2020; 132(6):1371-81. https://doi.org/10.1097/ALN.0000000000003256.

15. Gabriel RA, Sharma BS, Doan CN, Jiang X, Schmidt UH, Vaida F. A predictive model for determining patients not requiring prolonged hospital length of stay after elective primary total hip arthroplasty. Anesth Analg. 2019;129(1): 43-50. https://doi.org/10.1213/ANE.0000000000003798.

16. Carter EM, Potts HW. Predicting length of stay from an electronic patient record system: a primary total knee replacement example. BMC Med Inform Decis Mak. 2014;14(1):26. https://doi.org/10.1186/1472-6947-14-26.

17. Ledowski T, Falke L, Johnston F, Gillies E, Greenaway M, De Mel A, et al. Retrospective investigation of postoperative outcome after reversal of residual neuromuscular blockade: sugammadex, neostigmine or no reversal. Eur J Anaesthesiol. 2014;31 (8):423-9. https://doi.org/10.1097/EJA. 0000000000000010

18. Oh TK, Ji E, Na HS. The effect of neuromuscular reversal agent on postoperative pain after laparoscopic gastric cancer surgery: comparison between the neostigmine and sugammadex. Medicine (Baltimore). 2019; 98(26):e16142. https://doi.org/10.1097/MD.0000000000016142.

19. Carron M, Zarantonello F, Lazzarotto N, Tellaroli P, Ori C. Role of sugammadex in accelerating postoperative discharge: a meta-analysis. J Clin Anesth. 2017;39:38-44. https://doi.org/10.1016/j.jclinane.2017.03.004.

20. Wright CD, Gaissert HA, Grab JD, O'Brien SM, Peterson ED, Allen MS Predictors of prolonged length of stay after lobectomy for lung cancer: a Society of Thoracic Surgeons general thoracic surgery database riskadjustment model. Ann Thorac Surg. 2008;85(6):1857-65; discussion 65. https://doi.org/10.1016/.athoracsur.2008.03.024.

21. Jager KJ, van Dijk PC, Zoccali C, Dekker FW. The analysis of sunvival data: the KaplanMeier method. Kidney Int. 2008;74(5):560-5. https:/doi.org/10.1038/ki.2008.217.

22. Dudley WN, Wickham R, Coombs N. An introduction to survival statistics: Kaplan-Meier analysis. J Adv Pract Oncol. 2016;7(1):91-100. https://doi.org/1 0.6004/jadpro.2016.7.1.8.

23. Butterly A, Bittner EA, George E, Sandberg WS, Eikermann M, Schmidt U. Postoperative residual curarization from intermediate-acting neuromuscular blocking agents delays recovery room discharge. Br J Anaesth. 2010;105(3): 304-9. https://doi.org/10.1093/bja/aeq157.

24. Brueckmann B, Sasaki N, Grobara P, Li MK, Woo T, de Bie J, Maktabi M, Lee J, Kwo J, Pino R, Sabouri AS, McGovern F, Staehr-Rye AK, Eikermann M. Effects of sugammadex on incidence of postoperative residual neuromuscular blockade: a randomized, controlled study. Br J Anaesth. 2015;115(5):743-51. https://doi.org/10.1093/bja/aev104.

25. Murphy GS, Szokol JW, Avram MJ, Greenberg SB, Shear TD, Vender JS, Parikh KN, Patel SS, Patel A. Residual neuromuscular block in the elderly: incidence 
and clinical implications. Anesthesiology. 2015;123(6):1322-36. https://doi. org/10.1097/ALN.0000000000000865.

26. Lundquist H, Hedenstierna G, Strandberg A, Tokics L, Brismar B. CTassessment of dependent lung densities in man during general anaesthesia. Acta Radiol. 1995;36(6):626-32. https://doi.org/10.1177/0284185195036004 64.

27. Gan TJ. Poorly controlled postoperative pain: prevalence, consequences, and prevention. J Pain Res. 2017;10:2287-98. https://doi.org/10.2147/JPR. S144066.

28. Miskovic A, Lumb AB. Postoperative pulmonary complications. Br J Anaesth. 2017;118(3):317-34. https://doi.org/10.1093/bja/aex002

29. Bialka S, Copik M, Daszkiewicz A, Rivas E, Ruetzler K, Szarpak L, Misiolek H. Comparison of different methods of postoperative analgesia after thoracotomy-a randomized controlled trial. J Thorac Dis. 2018;10(8):4874-82. https://doi.org/10.21037/jtd.2018.07.88.

30. Guay J, Kopp S. Epidural pain relief versus systemic opioid-based pain relief for abdominal aortic surgery. Cochrane Database Syst Rev. 2016;1:CD005059.

31. Fernandez-Bustamante A, Frendl G, Sprung J, Kor DJ, Subramaniam B, Martinez Ruiz R, Lee JW, Henderson WG, Moss A, Mehdiratta N, Colwell MM, Bartels K, Kolodzie K, Giquel J, Vidal Melo MF. Postoperative pulmonary complications, early mortality, and hospital stay following noncardiothoracic surgery: a multicenter study by the perioperative research network investigators. JAMA Surg. 2017;152(2):157-66. https://doi.org/10.1001/jama surg.2016.4065.

32. Gagarine A, Urschel JD, Miller JD, Bennett WF, Young JE. Preoperative and intraoperative factors predictive of length of hospital stay after pulmonary lobectomy. Ann Thorac Cardiovasc Surg. 2003;9(4):222-5.

33. DeLuzio MR, Keshava HB, Wang Z, Boffa DJ, Detterbeck FC, Kim AW. A model for predicting prolonged length of stay in patients undergoing anatomical lung resection: a National Surgical Quality Improvement Program (NSQIP) database study. Interact Cardiovasc Thorac Surg. 2016; 23(2):208-15. https://doi.org/10.1093/icvts/ivw090.

34. Zhang Z, Mostofian F, Ivanovic J, Gilbert S, Maziak DE, Shamji FM, Sundaresan S, Villeneuve PJ, Seely AJE. All grades of severity of postoperative adverse events are associated with prolonged length of stay after lung cancer resection. J Thorac Cardiovasc Surg. 2018;155(2):798-807. https://doi.org/10.1016/.jtcvs.2017.09.094

35. Murphy GS, Szokol JW, Franklin M, Marymont JH, Avram MJ, Vender JS Postanesthesia care unit recovery times and neuromuscular blocking drugs: a prospective study of orthopedic surgical patients randomized to receive pancuronium or rocuronium. Anesth Analg. 2004;98(1):193-200 table of contents.

36. Beemer GH, Bjorksten AR, Dawson PJ, Dawson RJ, Heenan PJ, Robertson BA. Determinants of the reversal time of competitive neuromuscular block by anticholinesterases. Br J Anaesth. 1991;66(4):469-75. https://doi.org/10.1093/ bja/66.4.469.

\section{Publisher's Note}

Springer Nature remains neutral with regard to jurisdictional claims in published maps and institutional affiliations.

Ready to submit your research? Choose BMC and benefit from:

- fast, convenient online submission

- thorough peer review by experienced researchers in your field

- rapid publication on acceptance

- support for research data, including large and complex data types

- gold Open Access which fosters wider collaboration and increased citations

- maximum visibility for your research: over $100 \mathrm{M}$ website views per year

At BMC, research is always in progress.

Learn more biomedcentral.com/submissions 